\title{
Hemophagocytic syndrome due to infection by H1N1 influenza virus: Case
}

\section{report}

Hincapié Gustavo ${ }^{1}$, Bastidas Alirio ${ }^{1}$, Forero Yency ${ }^{2}$, Martin Daniel ${ }^{3}$, and Aponte Jorge ${ }^{4}$

1. Internal Medicine and Pulmonology, Hospital Militar, Bogotá, Colombia

2. PGY3 Internal Medicine, Universidad de La Sabana, Chía, Colombia

3. General Medicine, Universidad de La Sabana, Bogotá, Colombia

4. Internal Medicine Hospital Santa Clara, Hospital de la Samaritana, Bogotá, Colombia

\section{CASE STUDY}

Please cite this paper as: Hincapié G, Bastidas A, Forero Y, Martin D, Aponte J. Hemophagocytic syndrome due to infection by H1N1 influenza virus: Case report. AMJ 2018;11(12):533-537.

https://doi.org/10.21767/AMJ.2018.3502

\section{Corresponding Author:}

Jorge Enrique Aponte

Internal Medicine, Hospital de la Samaritana, Hospital de Santa clara Bogotá, Colombia

Email: jorgeapmo@unisabana.edu.co

\section{ABSTRACT}

A 31-year-old man presenting a dyspnoea, persistent fever, haemoptysis, a Leishmaniasis cutaneous record and recent close contact with a person diagnosed with influenza virus (H1N1). During admission to the emergency department, the patient rapidly progressed to respiratory failure requiring invasive mechanical ventilation and antibiotics because of suspected bacterial pneumonia. During his stay at the intensive care unit, he progressively developed bycytopenia, splenomegaly and reticulonodular lung opacities. Moreover, the bone marrow biopsy evidenced hemophagocytosis of lymphocytes and detection of H1N1 by Reverse Transcription Polymerase Chain Reaction (RT PCR). Hence, the case of hemophagocytic syndrome secondary to influenza virus H1N1, which was rapidly resolved after initiation of antiviral therapy, is presented hereof.

\section{Key Words}

Lymphohistiocytosis hemophagocytic, haemoptysis, H1N1

\section{Implications for Practice:}

\section{What is known about this subject?}

Few autopsy cases have reported hemophagocytic syndrome and H1N1 virus in DNA analysis; furthermore, rare literature reports have demonstrated that early treatment of H1N1 infection leads to better forecasts, and even, to a reduction of mortality.

\section{What new information is offered in this case study?}

Early oriented treatment to the identification of H1N1 virus leads to better livelihood when the hemophagocytic syndrome is developed.

3. What are the implications for research, policy, or practice?

Notwithstanding the oriented treatment, patients with persistent inflammatory response, absence or avoidance against the regulatory activity, should be investigated for hemophagocytic syndrome.

\section{Background}

A 31-year-old man presenting dyspnoea, persistent fever, haemoptysis, history of cutaneous a Leishmaniasis cutaneous record and recent close contact with a person diagnosed with influenza virus (H1N1).

\section{Case details}

A 31-year-old soldier was admitted to the emergency department with fever $\left(39^{\circ} \mathrm{C}\right)$, cough, haemoptysis, and dyspnoea for the past eleven days. His previous medical record was positive for cutaneous leishmaniasis treated with glucantime and positive for close contact to H1N1 influenza virus, plus the association with overcrowded spaces in his military facilities. When admitted, the patient presented a conjunctiva injection, hyaline rhinorrhoea and a usage of accessory respiratory muscles; the blood pressure was $130 / 85 \mathrm{mmHg}$, heart rate of 97 beats per minute, 
respiratory rate of 22 per minute, and temperature of $39^{\circ} \mathrm{C}$. The physical examination was positive for inspiratory wheezing and rales in lung fields with a palpable spleen; chest $\mathrm{x}$-ray showed nodular reticular opacities in all quadrants with bilateral pleural effusion and splenomegaly in abdominal ultrasonography; the blood analysis evidenced leukocytes of $1.840 \mu \mathrm{L}$., lymphocytes of $1,000 \mu \mathrm{L}$. (35.6 per cent), neutrophils of $780 \mu \mathrm{L}$. (55.6 per cent), haematocrit of 41.5 per cent, haemoglobin of $15.1 \mathrm{~g} / \mathrm{dl}$, and a platelets' count of $66,000 \mu \mathrm{L}$. In addition to the atypical lymphocytes in blood smear, elevated transaminases with alanine transaminase (ALT) $100 \mathrm{U} / \mathrm{L}$, aspartate transaminase (AST) $115 \mathrm{U} / \mathrm{L}$ without renal dysfunction or electrolyte imbalances were found. The inflammatory markers, such as the reactive protein $\mathrm{C}-9.6 \mathrm{mg} / \mathrm{dl}$, and the lactate dehydrogenase of $1,477 \mathrm{U} / \mathrm{L}$ were elevated. Finally, the metabolic profile showed normal glucose and thyroid function; nevertheless, isolated hypertriglyceridemia of $307.2 \mathrm{U} / \mathrm{L}$ was also found. Chest and abdominal computerized tomography (CT) (Figure 1) evidenced multiple non-cavitated nodules randomly distributed in all quadrants and peribronchial oedema associated with splenomegaly.

The patient progressed to hypoxemic respiratory failure, which required an invasive ventilatory support and a transfer to the intensive care unit (ICU), wherein, he persisted with bycytopenia: Leukocytes 2,900 $\mu \mathrm{L}$, lymphocytes 0.400 (14.7 per cent) $\mu \mathrm{L}$., neutrophils $2,210 \mu \mathrm{L}$. (75.8 per cent), haematocrit 38.2 per cent, haemoglobin of $13.6 \mathrm{mg} / \mathrm{dL}$, median corpuscular volume (VCM) 78.4fL, HCM: $27.9 \mathrm{pg}$, and platelets of $59,000 \mu \mathrm{L}$. Because of microbiological isolation absent, acute inflammatory response, and military facility overcrowding, the broad spectrum antimicrobial therapy was initiated with a poor response during the treatment. Well then, due to the continuous bycytopenia and persistent hypoxemia, a bone marrow aspiration was performed (Figure 2); likewise, due to the patient's past medical history of leishmaniasis, serological studies for fungal infection and parasites were conducted with negative results. The preliminary report of lymphocytic hemophagocytosis was presented with Gram stain from bone marrow analysis; which is why, a RT - PCR for H1N1 influenza virus from a nasopharyngeal swab was performed obtaining positive results. Patients comply with four criterions out of the criteria proposed for diagnosis hemophagoytic syndrome (persistent fever, splenomegaly, hemophagocytes in bone marrow and bycytopenia). Once the antiviral therapy was started, the patient had a complete resolution of symptoms, pancytopenia, hypertrigleridemia, and respiratory insufficiency without the need of immunosuppressive therapy.

\section{Discussion}

Lymphohistiocytic hemophagocytosis is a clinicopathological syndrome characterized by the infiltration of the bone marrow and the reticuloendothelial system by activated macrophages and histiocytes which lead to an uncontrolled phagocytosis of platelets, erythrocytes, lymphocytes, and precursor cells; ${ }^{1}$ it has been classified according to its underlying aetiology in two groups: primary (genetic), with early clinical presentation, or secondary (acquired), with emergence at any age and association to infectious pathogens, autoimmune, or neoplastic alterations. ${ }^{2}$

Overall impact is not known due to the under recognised and increased mortality, which, thanks to the excessive immune activation, is sometimes attributed to secondary diseases. ${ }^{2}$ Classification includes induced mechanisms, such as the virus-induced Lymphocytic Hemophagocytic Syndrome (SHLIV); some reviews describe frequencies, like the Epstein Barr virus (EBV) 70 per cent, herpes simplex virus (HSV) 50 per cent, and cytomegalovirus (CMV) 30-20 per cent with unknown data on incidence when coinfection with human immunodeficiency virus (HIV), rubella, Hepatitis A Virus (HAV) or respiratory syncytial virus (RSV) ${ }^{3-5}$ exist. With regards to the influenza virus (H1N1), autopsies of infected patients from the hemophagocytes in the bone marrow and spleen have been reported as well as the identification of H1N1 by DNA analysis in lung and nasal tissue; ${ }^{4}$ fact, which demonstrates the underdiagnosis of this syndrome in patients with acute respiratory infection who required management in ICUs. ${ }^{6,7}$

Through an observational study, conducted by Gernot Beutel et.al. with 25 critically ill patients diagnosed with H1N1, it was found that 9 (36 per cent) of the participants had hemophagocytic syndrome (HS), and from this subgroup, the calculated mortality range was 89 per cent, compared to 25 per cent in the group without (HS). The higher propencity in mortality, found in his cohort, had been already reported in 2013 with 24 cases, wherein, only 6 (25 per cent) survived to the presence of a severe inflammation with the resulting hemophagocytic syndrome due to H1N1. . $^{-10}$

Pathophysiology of SHLIV consists in an induction of a cytotoxic and macrophage Th1 immune response, which together, increase the efficacy of CD8 + T lymphocytes, which lead to recruitment and increase the proliferation of activated macrophages. ${ }^{2}$ On the other hand, antigen presenting cells promote the expansion of $\mathrm{CD} 8+\mathrm{T}$ lymphocytes, and, natural killer cells (NK), through the secretion of interleukin 2 (IL-2), Interferon gamma (INF- $\gamma$ ) ), 
tumour necrosis factor alpha (TNF- $\alpha)$, and colony stimulating factor for macrophages (M-CSF), lead to lymphohistiocytic proliferation and an uncontrolled cytokine storm responsible for signs and symptoms, as well as the characteristics of the laboratory findings of this syndrome $<50 \times 10^{9} /$ L),

Cytometry studies, carried out by Kereveur et al., evidenced on one side, an increase in the expression of the histocompatibility major complex class I and II (MHC), and on the other side, an increase in the expression of receptors for M-CSF and adhesion molecules (LFA-1, LFA-3), and ICAM-1 in splenic macrophages, which are related to a greater cellular adhesions capacity, an increased intracellular signalling, and a cytokine production and prolonged activation of macrophages. ${ }^{2,4}$ Thus, it might be concluded that the results of such studies are conclusive when describing that an increase in the production of INF, by $\mathrm{CD} 8+\mathrm{T}$ lymphocytes, not only serves as the main source for the production of inflammatory interleukins, but also, it plays an important role in the activation of macrophages and expression of molecules of tCMH type I and II.,

The aforementioned mechanisms might explain part of the SHILV; however, it is not specific for the H1N1 viral infection. Many of the reports and information found so far had been extrapolated from cytomegalovirus, Epstein Barr virus, and Herpes simplex virus infection. One of the few articles, that has specifically evaluated the effect of $\mathrm{H} 1 \mathrm{~N} 1$, was performed by Grant Schulert et al. describing 16 patients with a fatal outcome from H1N1 infection, and, in the autopsy, in the cohort, 81 per cent had evidence of hemophagocytosis; moreover, it was found that 36 per cent of the cases presented mutations in the PRF1 gene (encodes perforins) and LYST (encodes the granule trafficking protein), which, have been related to a damage in the cytotoxicity function of NK cells and the development of SHILV. ${ }^{11,12}$

The diagnosis is drawn upon clinical signs, symptoms, laboratory and histiopathological findings. The diagnostic guidelines were proposed by the International Histiocytic Society in 1991, updated in 2004, which could be found at the web site www.histio.org (Table 1). Well then, in one of the largest cohorts of patients diagnosed with $\mathrm{HLH}$, the predominant clinical signs were hepatomegaly in 95 per cent, lymphadenopathy in 33 per cent, neurological symptoms in 33 per cent, and maculopapular rash in 31 per cent. ${ }^{13}$ In the study, carried out by Aricò et al., ${ }^{14}$ fever and splenomegaly ran through 93 per cent and 97 per cent respectively. Nonetheless, the syndrome has a broad spectrum of presentations depending on the mutations and pathogens involved, making the symptoms, sometimes, nonspecific and challenging for the clinicians.

The treatment, either primary or secondary, includes protocols with immunosuppressive pharmacotherapy (Etoposide, dexamethasone, cyclosporin A), ${ }^{15,16}$ prophylactic antimicrobial therapy, and fresh frozen plasma or cryoprecipitated (if there is acute bleeding or platelet count $<50 \times 109 /$ L) ${ }^{9}$, alongside an adequate evaluation of cardiac function due to the risk of myocardial injury caused by inflammation or drug toxicity. ${ }^{1,17}$

Treatment for SHLIV secondary to the H1N1 influenza is not well known, and there are not enough data in literature. Nonetheless, an immunomodulatory therapy ${ }^{18}$ with steroids, immunoglobulin (Intravenous IV Immunoglobulin $\mathrm{G})$, and even, plasmapheresis, is proposed, on one side, to reduce $\mathrm{TH} 1$ inflammatory response, and on the other side, to prevent the progression and maintenance of cellular energy caused by spinal cord involvement. Well then, caution should be required due to the documented literature with increased mortality, secondary to viral pneumonias and the use of steroid therapy. ${ }^{9,19-21}$

The antiviral utilized is proposed as an early management, which, as seen in this study, led to a complete resolution of symptoms and not associated mortality. This case is presented to illustrate how active research of pathogens should be carried out in patients with high risk of H1N1 viral infection.

\section{Conclusion}

Increasing the inflammatory response in critically ill patients, who do not response to specific therapy, and even, fail to compensate with an anti-inflammatory response, leads to think in an alternative diagnosis and to investigate further when cytopenias are presented. By and large, this report pretends to review and show the development of hemophagocytic syndrome secondary to coinfection by an influenza virus in a young patient who responded positively to the use of antiviral therapy.

\section{References}

1. Zheng $Y$, Yang $Y$, Zhao $W$, et al. Novel swine-origin Influenza A (H1N1) virus-associated hemophagocytic syndrome-A first case report. Am J Trop Med Hyg. 2010;82(4):743-5. Available from: http://www.ncbi.nlm.nih.gov/pubmed/20348529

2. Gupta S, Weitzman S. Primary and secondary hemophagocytic lymphohistiocytosis: clinical features, 
pathogenesis and therapy. Expert Rev Clin Immunol. 2010;6(1):137-54. Available from: http://www.ncbi.nlm.nih.gov/pubmed/20383897

3. Raschke RA, Garcia-Orr R. Hemophagocytic Lymphohistiocytosis. Chest. 2011;140(4):933-8. Available from: http://www.ncbi.nlm.nih.gov/pubmed/21737492

4. Kereveur A, Mcllroy D, Samri A, et al. Up-regulation of adhesion and MHC molecules on splenic monocyte/macrophages in adult haemophagocytic syndrome. Br J Haematol. 1999;104(4):871-7. Available from: http://doi.wiley.com/10.1046/j.13652141.1999.01247.x

5. Harms PW, Schmidt LA, Smith LB, et al. Autopsy findings in eight patients with fatal H1N1 Influenza. Am J Clin Pathol. 2010;134(1):27-35. Available from: http://www.ncbi.nlm.nih.gov/pubmed/20551263

6. Rouphael NG, Talati NJ, Vaughan C, et al. Infections associated with haemophagocytic syndrome. Lancet Infect Dis. 2007;7(12):814-22. Available from: http://www.ncbi.nlm.nih.gov/pubmed/18045564

7. Watanabe M, Shibuya A, Okuno J, et al. Hepatitis A virus infection associated with hemophagocytic syndrome: report of two cases. Intern Med. 2002;41(12):1188-92. Available

from: http://www.ncbi.nlm.nih.gov/pubmed/12521213

8. Beutel G, Wiesner O, Eder M, et al. Virus-associated hemophagocytic syndrome as a major contributor to death in patients with 2009 influenza A (H1N1) infection. Crit Care. 2011;15(2):R80. Available from: http://www.ncbi.nlm.nih.gov/pubmed/21366922

9. Asai $N$, Ohkuni $Y$, Matsunuma R, et al. A case of novel swine influenza A (H1N1) pneumonia complicated with virus-associated hemophagocytic syndrome. J Infect Chemother. 2012;18(5):771-4. Available from: http://www.ncbi.nlm.nih.gov/pubmed/22286408

10. Demircioğlu F, Kazancı E, Genç DB, et al. H1N1 InfectionRelated Hemophagocytic Lymphohistiocytosis in a Child. Turkish J Haematol. 2013;30(4):426-8. Available from: http://www.ncbi.nlm.nih.gov/pubmed/24385840

11. Jessen B, Maul-Pavicic A, Ufheil $H$, et al. Subtle differences in CTL cytotoxicity determine susceptibility to hemophagocytic lymphohistiocytosis in mice and humans with Chediak-Higashi syndrome. Blood. 2011;118(17):4620-9. Available from: http://www.ncbi.nlm.nih.gov/pubmed/21878672

12. Schulert GS, Zhang $M$, Fall $N$, et al. Whole-Exome Sequencing Reveals Mutations in Genes Linked to Hemophagocytic Lymphohistiocytosis and Macrophage Activation Syndrome in Fatal Cases of H1N1 Influenza. J Infect Dis. 2016;213(7):1180-8. Available from: http://www.ncbi.nlm.nih.gov/pubmed/26597256

13. Trottestam $H$, Horne $A$, Aricò $M$, et al. Chemoimmunotherapy for hemophagocytic lymphohistiocytosis: long-term results of the HLH-94 treatment protocol. Blood. 2011;118(17):4577-84. Available from: http://www.ncbi.nlm.nih.gov/pubmed/21900192

14. Aricò $M$, Janka G, Fischer $A$, et al. Hemophagocytic lymphohistiocytosis. Report of 122 children from the International Registry. FHL study group of the histiocyte society. Leukemia. 1996;10(2):197-203. Available from: http://www.ncbi.nlm.nih.gov/pubmed/8637226

15. Jordan MB, Allen CE, Weitzman S, et al. How I treat hemophagocytic lymphohistiocytosis. Blood. 2011;118(15):4041-52. Available from: http://www.ncbi.nlm.nih.gov/pubmed/21828139

16. Henter J-I, Samuelsson-Horne A, Aricò $M$, et al. Treatment of hemophagocytic lymphohistiocytosis with HLH-94 immunochemotherapy and bone marrow transplantation. Blood. 2002;100(7):2367-73. Available from: http://www.ncbi.nlm.nih.gov/pubmed/1954380

17. Dierickx D, Cortoos A, Vanderschueren S. The haemophagocytic syndrome. Acta Clin Belg. 2011;66(6):448-52. Available from: http://www.ncbi.nlm.nih.gov/pubmed/22338310

18. Zhang XY, Ye XW, Feng DX, et al. Hemophagocytic Lymphohistiocytosis induced by severe pandemic Influenza A (H1N1) 2009 virus infection: A case report. Case Rep Med. 2011;2011:1-3. Available from: http://www.hindawi.com/journals/crim/2011/951910/

19. Martin-Loeches I, Lisboa T, Rhodes A, et al. Use of early corticosteroid therapy on ICU admission in patients affected by severe pandemic (H1N1)v influenza A infection. Intensive Care Med. 2011;37(2):272-83. Available from: http://www.ncbi.nlm.nih.gov/pubmed/21107529

20. Willekens C, Cornelius A, Guerry MJ, et al. Fulminant hemophagocytic lymphohistiocytosis induced by pandemic A (H1N1) influenza: A case report. J Med Case Rep. 2011;5:280. Available from: http://www.ncbi.nlm.nih.gov/pubmed/21722406

21. Ay Y, Yildiz B, Unver $H$, et al. Hemophagocytic lymphohistiocytosis associated with H1N1 virus infection and visceral leishmaniasis in a 4.5-month-old infant. Rev Soc Bras Med Trop. 2012;45(3):405-6. Available from: http://www.scielo.br/scielo.php?script=sci_arttext\&pid= S0037-86822012000300026\&lng=en\&tlng=en

\section{PEER REVIEW}

Not commissioned. Externally peer reviewed. 


\section{CONFLICTS OF INTEREST}

The authors declare that they have no competing interests.

\section{FUNDING}

None

\section{PATIENT CONSENT}

The authors, Hincapié G, Bastidas A, Forero Y, Martin D, Aponte J, declare that:

1. They have obtained written, informed consent for the publication of the details relating to the patient(s) in this report.

2. All possible steps have been taken to safeguard the identity of the patient(s).

3. This submission is compliant with the requirements of local research ethics committees.

Figure 1: Chest CT scan: multiple nodules non-cavitated randomly distributed in both lung fields

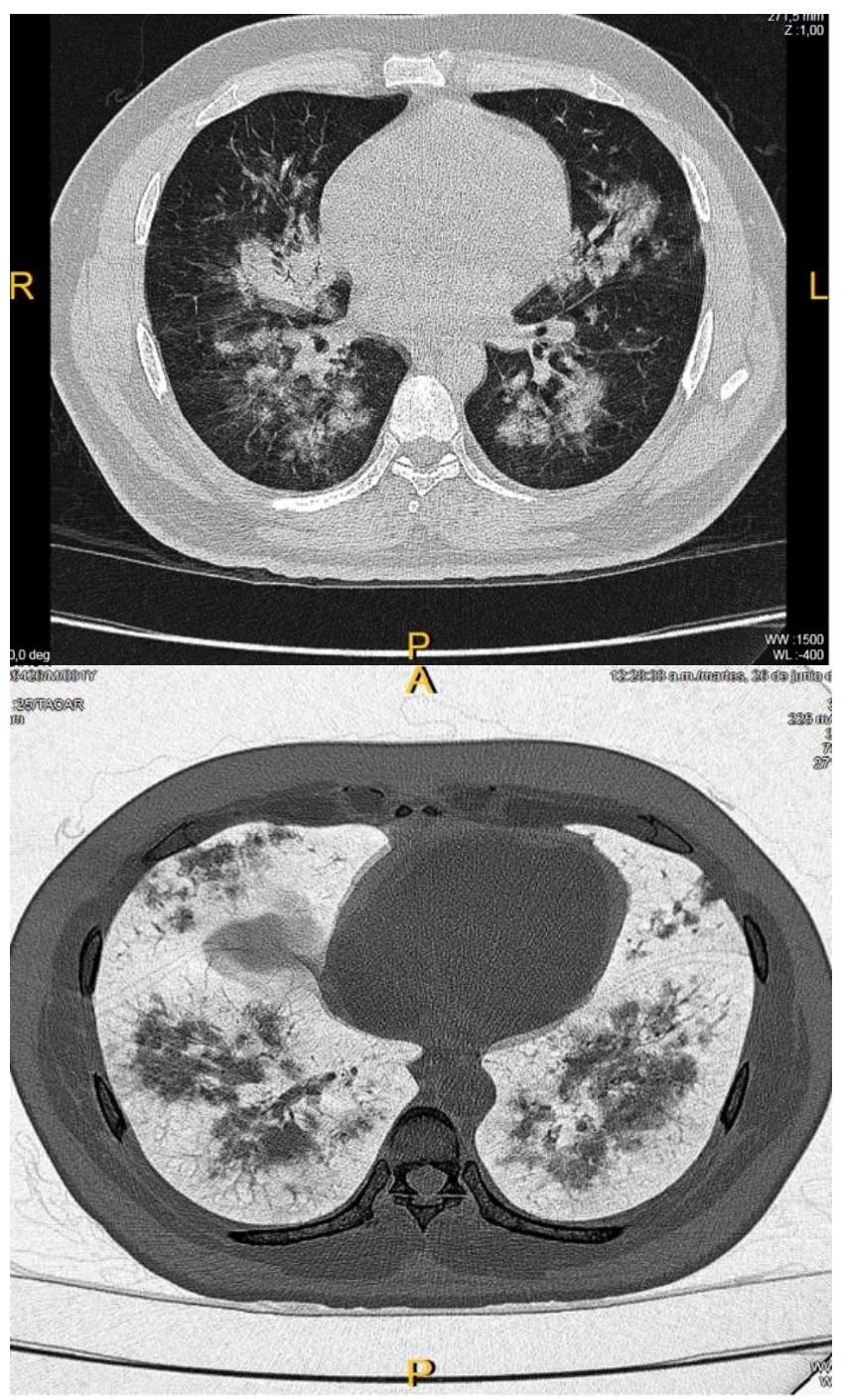

Figure 2: Arrow shows a macrophage in bone marrow aspirate with phagocytosis of lymphocytes (Hematoxylin and eosin stain, original visual field 100x)

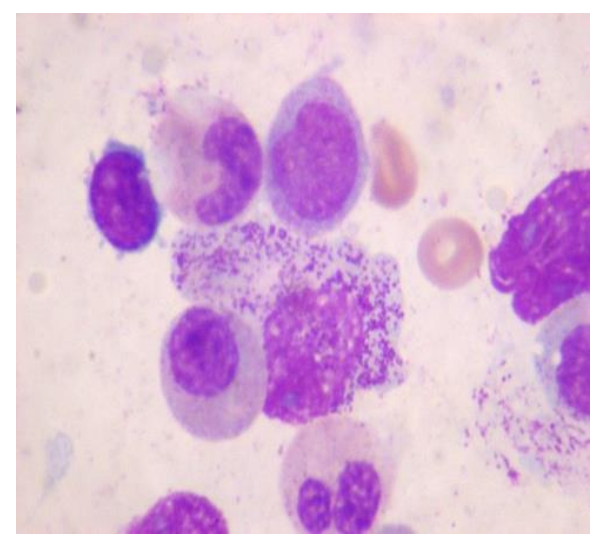

Table 1: Diagnostic criteria Histiocyte Society, proposed in 2004 and revised in 2007

\section{Criteria for Hemophagocytic Syndrome}

1. Molecular diagnosis consistent with hemophagocytic syndrome (mutations in PRF, SAP o MUNC-13) and/or

2. Five out of eight criteria

a. Persisten fever.

b. Splenomegaly.

c. Bycitopenia (compromise of $>2$ or more of cell linages, hemoglobin less than $9 \mathrm{mg} / \mathrm{dl}$, platelet count less than $100,000$, neutrophil count less than 1,000 células $/ \mu L)$

d. Hypertriglyceridemia (greater than $265 \mathrm{mg} / \mathrm{dl}$ ) and/or hypofibrinoginemia (fibrinogen less than $150 \mathrm{mg} / \mathrm{dl}$ ).

e. Hemophagocytes in bone marrow, spleen or lymph nodes without any signs of subyacent neoplasia.

f. Hyperferritinemia (ferritine greater than $500 \mathrm{ng} / \mathrm{ml}$ ).

g. Increase soluble CD25 (greater than 2,400IU/ml)

h. Absent or low activity of natural killer cells. 